\title{
What is a 'competitive return' to a landowner? Parkhurst Road and the new UK planning policy environment
}

Article

Accepted Version

Crosby, N. and Wyatt, P. (2019) What is a 'competitive return' to a landowner? Parkhurst Road and the new UK planning policy environment. Journal of Property Research, 36 (4). pp. 367-386. ISSN 1466-4453 doi:

https://doi.org/10.1080/09599916.2019.1690028 Available at https://centaur.reading.ac.uk/87519/

It is advisable to refer to the publisher's version if you intend to cite from the work. See Guidance on citing.

To link to this article DOI: http://dx.doi.org/10.1080/09599916.2019.1690028

Publisher: Routledge

All outputs in CentAUR are protected by Intellectual Property Rights law, including copyright law. Copyright and IPR is retained by the creators or other copyright holders. Terms and conditions for use of this material are defined in the End User Agreement.

www.reading.ac.uk/centaur 
Central Archive at the University of Reading

Reading's research outputs online 
What is a 'competitive return to a landowner'? Parkhurst Road and the new UK planning policy environment

Neil Crosby*

Professor of Real Estate

Department of Real Estate and Planning, University of Reading, Whiteknights, Reading, RG6 6UD

Email: f.n.crosby@rdg.ac.uk

*Corresponding Author

Peter Wyatt

Professor of Real Estate Appraisal

Department of Real Estate and Planning, University of Reading, Whiteknights, Reading, RG6 6UD

Email: p.wyatt@rdg.ac.uk 


\title{
What is a 'competitive return' to a landowner? Parkhurst Road and the new UK planning policy environment
}

\begin{abstract}
In the UK, contributions from landowners towards the provision of affordable housing are obtained through a process of negotiation that centres on the financial viability of each development proposal. National Planning Practice Guidance, first published in 2014 and recently revised in 2018 and 2019, provides the Government framework for these negotiations and sets parameters for the financial viability appraisals. Failure to achieve levels of affordable housing set out in local plans has been attributed to 'gaming' strategies employed by landowners and developers within viability negotiations. This paper examines how planning guidance has influenced financial viability appraisals.

A key issue within these appraisals is the determination of a suitable return to the landowner, known as Benchmark Land Value. Using a case study approach to investigate two planning appeals and a subsequent High Court decision concerning a residential development site in London, this paper demonstrates how planning policy and practice guidance on viability can lead to reduced planning obligations being delivered. It identifies the technical concerns that need to be addressed to enable appraisals to determine land prices that are fair to landowners, whilst delivering policy-compliant levels of affordable housing, and discusses whether the revised National Planning Guidance has made those changes.
\end{abstract}

\section{Keywords}

UK; development viability assessment; landowner return; development appraisal; planning obligations 


\section{Introduction}

When permission is granted for development in England, local planning authorities can stipulate planning obligations. These obligations legally require the delivery of infrastructure, community services and, most importantly as far as this paper is concerned, the provision of affordable housing. To prevent these planning obligations from stifling development, they must pass a financial viability test which checks whether the planning obligations can be delivered without deterring landowners and developers from bringing developments forward. This viability test has become a contested issue since its formal introduction in 2012; developers have been able to reduce planning obligations, and the amount of affordable housing in particular, by influencing input parameters and model assumptions of the financial viability appraisal (DCLG, 2017, Para 106). Recognising this influence, in 2018, the UK Government issued a new National Planning Policy Framework (MHCLG, 2018a) and revised guidance on viability in planning (MHCLG, 2018b) that shifted the requirement for a viability test away from site-by-site negotiations of development viability, towards an assessment that takes place at an area-wide scale during the formation of local development plans.

Whether for area-wide plan making or for site-specific decision taking, the assessment of financial viability centres on the application of a financial appraisal model. The model requires estimates of the costs of the development scheme (including the cost of planning obligations and a return to the developer) and the value that might be obtained once the scheme is complete. If the value is sufficiently higher than the costs, and the surplus (or residual) amount is enough to motivate the landowner to sell, then the scheme is considered viable. However, there is no research on what return landowners seek when they are considering the sale of land for development, or how it might vary over time, by type of development or location. As a result, its assessment has proved to be highly contestable. The Government's viability guidance attempts to clarify the return to the landowner or 'Benchmark Land Value' (BLV) but so far this has failed to resolve the issue.

This paper investigates the concept and application of BLV in financial viability appraisals. The framework for this investigation is founded on the notion of the development process as a social construct, one where there are multiple stakeholders, and which has undergone a process of marketization and compartmentalisation. This has led to the increased role of experts in specific components of the development management process. Financial viability appraisal is one such component, and a key one. Market-orientated experts have been free to develop calculative practices and strategic behaviours that may have undermined affordable housing policy.

The next section of the paper establishes the theoretical framework for the research. It places the current debate on financial viability in planning within the literature that argues that development is a social process that has become market-dominated, fragmented and calculative. The paper then reviews the literature surrounding financial viability appraisals in general and BLV in particular. The changing policy environment is discussed, before examining the details of a landmark planning appeal relating to a development site on Parkhurst Road in the London Borough of Islington which went to review in the High Court. The paper concludes with a discussion of the questions arising from the Parkhurst Road case, linking them back to the literature and recommending practical solutions. 


\section{Housing development decision-making}

Figure 1 illustrates the development process as a social construct where there are multiple stakeholders. Focusing on the supply of housing land from private landowners and the regulation of that supply by local planning authorities, market-orientated experts have developed calculative practices and behavioural strategies to challenge local planning policy, particularly in relation to affordable housing. In an attempt to set the 'rules of the game', central Government introduced policy and practice guidance and subsequently, in 2014, revised planning practice guidance in relation to financial viability. The case study in section 4 below demonstrates how landowners and developers responded to the guidance.

\section{Figure 1 here}

The framework for this investigation is founded on research in the 1980s and 1990s that examined the relationship between the planning system and the property development industry. The increasing awareness and understanding of the relationship between these two activities led to the contention that the development process is a social construct, one where there are multiple actors. Healey and Barratt (1990) and Healey (1991 and 1992a) argued that, to understand the development process, it is necessary to understand how actors in that process behave; how they define their interests, formulate their strategies, create their roles and deploy resources. Henneberry and Parris (2013) emphasised the importance of developing this understanding at the project level, where 'local personal relations and corporate networks' underpin project dynamics (p227).

Building on this work and recognising the importance of the developer as a market-led actor, Coiacetto (2001) argued that, to fully understand how developers behave, it is important for planning practice to recognise their diversity. He suggested that, rather than one homogeneous developer typology, there was a range, from local landowner-developers through to showpiece and specialist developers. All Coiacetto's developer types are private sector and market led. Monk and Whitehead (1999) contrasted the behaviour of landowners and planners in high and low demand locations. They found that the impact of regulatory constraint on land and house prices significantly modified the behaviour of landowners. In an area of little constraint, when house prices increased, developers moved in and land prices increased. But they argue that these developers showed little understanding of local markets and were caught out when the market declined.

Adams and Tiesdell (2010) regarded planners as market actors too, framing and reframing market conditions with market-shaping instruments such as plans, development control and planning obligations. Yet, they argued, planners do not necessarily see themselves in this role. Basing their research on the Scottish Government's perception of developers, Adams et al (2012) found that there was limited understanding of what drives the development process or what motivates individual developers. Instead, the 'notional property developer' was perceived as a 'malleable and potentially compliant partner with shared objectives of the state' (p2577).

There is, therefore, recognition of the market-orientation of the development process. But, if the state is unfamiliar with its workings, then 'conflict may arise where new principles are introduced, as in the current debate over whether planning authorities can require developers to build a 'quota' of social 
housing' (Healey, 1992b: 417). Healey suggested that 'the state has absorbed market criteria into its decision-making framework, while market actors recognise the weight which must be given to political demands' (p417). This mutual recognition of each actor's objectives has manifested itself in the form of a financial model (McAllister et al, 2013). The model, which is based on the conventional method for estimating land value of development sites, is employed by local planning authorities to determine viable levels of planning obligations. As use of the model expanded so did guidance on how it should be used, with three of the most important guidance documents published by the Local Housing Delivery Group (2012), RICS (2012) and Planning Practice Guidance from Government (DCLG, 2014). Christophers (2014) went on to argue that, rather than a model being used to describe the reality of development appraisal, the model now shapes reality; determining rather than reflecting behaviour of key actors, such as landowners and developers.

Developing this theme, using a case study of development planning in London, Raco et al (2016) argue that local government is 'increasingly dominated by anti-democratic development 'machines', characterised by new assemblages of public- and private-sector experts. These machines reflect and reproduce a type of development politics in which there is greater emphasis on pragmatic realism and the politics of delivery' (p216). Parker et al (2018) refer to the fragmented planning system that has emerged in England. More consultants, specialists and non-planners has led to a 'compartmentalisation of planning into a series of discrete and deliverable elements ... This opens the planning process to a range of private companies whose expertise is sold on the basis that it is directly targeted to achieving specific outcomes (solutionism) and meeting particular client needs' (p745). Financial viability appraisal is a case in point: specialist consultants, bespoke financial models, and technical terminology 'introduce new forms of knowledge that may confound local politicians and public sector officials' (p746). McAllister (2017) identifies the literature surrounding concerns that this asymmetry of expertise lies firmly in the hands of landowners, developers and site promotors. He reviewed the policy and technical issues surrounding financial viability appraisals within the UK planning system including: incentives for developers and landowners to bias appraisals; the intrinsic uncertainty within appraisals that allows that to occur; the economic dependence of many viability consultants on developers and land owners; and the lack of transparency within the viability appraisal process. Colenutt et al (2015) and Flynn (2016) identify increasing concern within communities and local government at the use of financial viability appraisals within the planning system.

These assertions imply that this asymmetric knowledge and understanding are held within the developer/landowner community and therefore bias the outcomes in ways that are not easy to prove. The fall in affordable housing provision by the seven major housebuilders between 2010 and 2017 from $40 \%$ to $19 \%$ of total completions while their average return on capital employed rose from under $7 \%$ to over $32 \%$ is suspicious but not incontrovertible (Crosby, et al, 2019). However, despite the lack of expertise generally within councils identified in the literature above and the concerns about viability and reducing developer contributions, one council faced with a number of these issues decided that "more needed to be done" (Quote from email from Islington Borough Council Planning Officer). This LPA, faced with a number of large sites with major disputes regarding developer contributions, decided to take steps to try and reverse the reducing developer contribution trend. The outcome of this resistance is partly responsible for wholesale changes to the Planning Practice Guidance (MHCLG, 2018b), made with the express intention to stop any potential misuse of the viability system. 
In order to identify whether these concerns were justified, it is necessary to show whether the calculative practice, and the policy framework and practice guidance which underpins its operation, is actually capable of being manipulated and, if it is, whether there is evidence of this occurring within actual cases. With this in mind, the next section of the paper describes how market-orientated experts in financial appraisals have developed calculative practices and behavioural strategies that seek to undermine affordable housing policy.

\section{The calculative turn in development decision-making}

Coleman, et al (2013) explain how financial viability modelling for UK planning purposes differs from its use by developers for investment decisions. These differences centre on the simplified nature of the model and the absence of growth forecasts when it is used for planning purposes. Crosby and Wyatt $(2015 ; 2016)$ focus on the use of development appraisals in the UK planning system and the specific issue of BLV. They used case studies of planning appeals to examine how BLV has been calculated and found it was based on several alternatives:

(a) Price paid for the site. This is an example of how landowners and developers attempted to game the financial viability appraisal process in its early days. A developer would purchase land at a price that does not factor in policy-compliant planning obligations, and then use that price to argue that policy-compliant planning obligations would be unviable. For example, in a planning appeal for a residential development in central London in $2014^{1}$, the appellant supplied evidence to support the BLV assumption that included an independent valuation of the existing use, the purchase price of the site and two offers to purchase the site. The inspector preferred this evidence to the council's residual valuation, which included a policy compliant level of affordable housing. Reliance on this classic circular argument has now ceased following guidance from Government in 2014 (DCLG, 2014, paragraphs 14 and 23). This new guidance stated that the price actually paid for a site should not be used in the viability study. The wider consequences of PPG (2014) will be addressed in the next section of this paper.

(b) Existing use value plus a premium (or EUV+ for short). Although Crosby and Wyatt (2016) identified cases that had used EUV as the basis for benchmark land value, they also noted that a premium would be needed to persuade landowners to release the land for development. Having noted the absence of a framework for quantifying the premium in EUV+, they warned against reliance on market evidence of land transactions when attempting to determine the quantum of the premium because the same circular argument as (a) arises if those transactions are not policy-compliant. The use of EUV+ as a basis for BLV is the focus of the revised National Planning Policy Framework (MHCLG, 2018a) and this will be addressed in the next section. Local Housing Delivery Group (2012) endorsed the use of this approach but was less precise on how to address the fundamental problem of assessing the level of premium. The Local Housing Delivery Group Report recognised the need to persuade landowners to release land voluntarily and that the level of land prices was an important

\footnotetext{
${ }^{1}$ 271-281 King Street, London, W6 9LZ (APP/H5390/A/13/2209347)
} 
factor but did not advocate using market values. "Reference to market values can still provide a useful 'sense check' on the threshold values that are being used in the model (making use of costeffective sources of local information), but it is not recommended that these are used as the basis for the input to a model." (Local Housing Delivery Group, 2012, p29).

(c) Market Value: This is based on an analysis of market evidence of comparable land transactions. This approach to BLV has been used in several planning appeal cases, despite the Local Housing Delivery Group guidance. Crosby and Wyatt (2016) noted that the market valuation must be on a development scheme that is policy-compliant, otherwise the circular argument noted in (a) arises. However, the early guidance on viability from Government (DCLG, 2014) implied that a body of comparable evidence proved compliance, and inspectors had adopted that approach. For example, in an appeal against a refusal of planning permission for a residential development in north London in $2012^{2}$, the inspector regarded as reasonable the appellant's evidence, which comprised transactions on various development site locations with a range of schemes.

(d) Sharing the uplift in value. This requires two valuations of the land; one assumes continuation of existing use and the other assumes development but disregards any planning obligations. The difference between these two valuations, the uplift, would be shared between the planning authority and landowner. This approach was recommended by the inspector in a 2008 planning appeal in Bristol ${ }^{3}$ and was used in an appeal in Reading in $2012^{4}$ where the inspector agreed that the landowner and planning authority share the uplift equally. In other words, BLV was set at $50 \%$ of the uplift. Crosby and Wyatt (2016) suggested that, for site-specific financial viability appraisals, sharing the uplift was the best way of determining BLV within the policy framework existing at the time, but recognised that it would require a policy decision on what the split should be. Indeed, Chris Phelp MP has since suggested that around half of the uplift should be captured ${ }^{5}$ and the Peel Group, in evidence to the House of Commons Select Committee enquiry into Land Value Capture in September 2018, suggested a 60\%/40\% landowner/planning authority allocation as part of a range of benchmarks ${ }^{6}$.

This variety of practice in setting BLV evolved under a particular policy and practice framework, specifically DCLG (2012, 2014), Local Housing Delivery Group (2012) and RICS (2012). The 2012 National Planning Policy Framework (DCLG, 2012) and the National Planning Practice Guidance on viability (DCLG, 2014) required local authorities to ensure that both landowner and developer receive competitive returns when setting planning obligations. Consequently, levels of landowner return have been maintained despite widespread acknowledgement that the cost of planning obligations needs to be paid

\footnotetext{
${ }^{2}$ Land north of St Edmund's Terrace, London, NW8 7QU (APP/X5210/A/12/2173598)

${ }^{3}$ Planning appeal reference number: APP/P0119/A/08/2069226

${ }^{4}$ Planning appeal reference number: APP/X0360/A/12/2179141

5 'Green, Pleasant and Affordable' by Onward, June 2018. p22: (CPS, Homes for Everyone, December 2017)

${ }^{6}$ https://www.parliament.uk/business/committees/committees-a-z/commons-select/communities-and-localgovernment-committee/inquiries/parliament-2017/land-value-capture-inquiry-17-19/
} 
for out of increases in land value resulting from the grant of development rights. For example, Sayce et al (2017) and McAllister et al (2018) show how landowners in London have successfully negotiated levels of planning obligations below policy requirements by claiming that their levels of return are no longer competitive. This was achieved by a process that allowed market evidence of land prices (rather than the actual price) to dominate the appraisal. Planning Practice Guidance (DCLG, 2014) stated the following for both area-wide (paragraph 14) and for site-specific (paragraph 23) financial viability assessments:

"Central to the consideration of viability is the assessment of land or site value. The most appropriate way to assess land or site value will vary but there are common principles which should be reflected.

In all cases, estimated land or site value should:

- reflect emerging policy requirements and planning obligations and, where applicable, any Community Infrastructure Levy charge;

- provide a competitive return to willing developers and land owners (including equity resulting from those building their own homes); and

- be informed by comparable, market-based evidence wherever possible. Where transacted bids are significantly above the market norm, they should not be used as part of this exercise."7

Concatenating the first and third bullet points, BLV should be informed by comparable, market-based evidence of similar land value transactions that are policy compliant. This creates a circularity: if market-based evidence is used to establish the BLV, and shows that policy levels of affordable housing are not viable because they do not leave a competitive return for the developer, then the BLV (and the market evidence supporting it) is not policy compliant. In such cases, planning inspectors were forced to decide where to put the emphasis, on policy compliance or on market evidence. If market evidence dominates the BLV assessment, and developer's return is also fixed at a "competitive" level, planning obligations become the moveable item. Increases in market land values can be used to increase the BLV and reduce planning obligations. The case study in Section 4 below reveals this circularity in practice. This dilemma called into question what policy compliance means. Is it the target level of affordable housing or is it some lower amount that is actually delivered? If negotiated settlements or third-party determinations upon appeal result in lower levels of affordable housing, do these lower levels become policy compliant as they are the maximum that can be afforded?

The literature suggests that there may be an imbalance of power and knowledge within the viability process. But it also suggests that the policy and practice guidance has been interpreted to favour

\footnotetext{
${ }^{7}$ The wording shown is for Paragraph 14. Paragraph 23 is identical except for one sentence added to the opening statement of the paragraph and a slight tweak to the next sentence. In addition, the word emerging was omitted from the first bullet point.
} 
developer/landowner interests. Not only do they have the motivation, the planning guidance gave them the means via the circularity identified in the literature.

The revised national planning guidance on viability (MHCLG, 2018b) addresses the circularity issue by changing the basis of BLV from one that was informed by market-based evidence wherever possible to one that is primarily based on the site's existing use value plus a premium, which is the minimum return to incentivise a reasonable landowner to willingly sell. The guidance states that estimation of the premium may be informed by market evidence (including land transactions) and evidence of precedents set by other viability assessments, so it remains to be seen whether this provides sufficient clarity. Importantly, it states that evidence should reflect the cost of policy compliance and that policy compliance means the delivery of the planning requirements set out in the plan. But it now states in a 2019 amendment to MHCLG (2018b) that land transactions should only be used to cross-check the BLV and level of the premium above EUV; a reference back to Local Housing Delivery Group report which suggests that market values are a sense-check rather than the basis of BLV.

It is within this changing Government policy and guidance framework that the Parkhurst Road case is evaluated. Part of the resistance to the trend in reducing developer contributions by Islington Borough Council was to take a landmark case through the courts; from the original planning appeal, heard before the Planning Inspectorate in 2015, to a subsequent planning application, a refusal and then to a planning appeal heard in 2017. This result was itself appealed to the High Court in 2018. The Parkhurst Road appeals and High Court case were heard under earlier policy guidance, so it provides some evidence of whether the viability problems were based on power and knowledge asymmetry or were entrenched in the policy regime. From that, we can try and assess whether the new planning practice regime will solve the problems wholly, partly or at all.

\section{Parkhurst Road Case study}

The 0.58-hectare site, which was used as a training centre for the Territorial Army, is situated in a largely residential street in the London Borough of Islington. No longer required for military purposes, in 2013 the site was sold by the Ministry of Defence to Parkhurst Road Limited (PRL) for approximately $£ 13 m$. Due to the previous military use, the existing use value was assessed at $£ 750,000$. The site was allocated for residential use in the local plan and, in December 2013, PRL submitted a planning application for 150 dwellings, $21 \%$ of which were to be affordable homes. Following comments from the Council the number of dwellings was reduced to $112,14 \%$ of which were to be affordable homes.

The application was refused on three grounds, one of which was that "...the applicant failed to demonstrate that the proposed development will provide the maximum reasonable amount of affordable housing taking account of the borough-wide target of $50 \% \ldots$ and has failed to provide an appropriate benchmark land value for the site." ${ }^{8}$

${ }^{8}$ Planning application reference number: P2013/4950/FUL 
PRL appealed against the refusal of permission and, in relation to the ground described above, argued that, even though the borough-wide target for affordable housing was $50 \%$, the provision of affordable housing on individual sites could vary between $0 \%$ and $100 \%$. A financial viability appraisal was submitted by PRL to demonstrate that $14 \%$ was the maximum reasonable amount of affordable housing for this particular site. The main inputs and output from PRL's and the Council's financial viability appraisals are shown in Table 1.

\section{Table 1 here}

Oddly, the appellant's $£ 13 m$ site value remained the same despite a reduction in the number of units in the proposed development from 150 to 112 which should have reduced the gross development value. Ordinarily this would be expected to reduce the value of the site, all else being equal, unless the developer had already assumed this lower density when purchasing the site. However, what changed in the developer's viability assessment was the amount of affordable housing, from $21 \%$ to $14 \%$.

PRL's appraisal required site value as an input and that input was based on market evidence of land prices. PRL argued that the inclusion of site value based on market prices would account for the cost and level of affordable housing that the market perceives as financially viable. The output from the PRL's appraisal was an estimate of developer's profit and it was this that was benchmarked. By adopting this approach, PRL avoided the problem of having to explicitly state a BLV.

In contrast, the Council's appraisal included developer's profit as an input and site value as the output. The amount of developer's profit was $£ 7 \mathrm{~m}$, equivalent to $20 \%$ of development cost, a widely accepted rule of thumb in the real estate development industry. Unlike PRL's 14\%, the Council assumed the proportion of affordable housing to be $40 \%$. This led to a lower construction cost than PRL (most likely due to the reduced build cost associated with the now much larger proportion of affordable housing) and a development value that was also lower than PRL (most likely as a result of the lower value attached to affordable housing compared to market housing). The Council's approach modelled a policy compliant level of affordable housing, although $40 \%$ rather than $50 \%$ was used because this was purported to be more in line with most of the market evidence (the rationale for ignoring some of the evidence was the circularity issue discussed above).

PRL and the Council largely agreed on the other inputs into the appraisal, chiefly construction costs and the value of the completed scheme. Site value and the level of affordable housing were the disputed assumptions. The essential distinction between the parties' approaches to viability appraisal was that PRL regarded the market-based site value as a key determinant of the level of affordable housing provision, whereas the Council regarded its policy target for affordable housing as a key determinant of site value. The dispute stems from disagreement over what is the 'correct' site value (or competitive return to the landowner) and what is the 'correct' (or policy compliant) amount of affordable housing?

This presents a problem; there are two unknowns, and one needs to be fixed to calculate the other. Paragraph 14 (and 23) of the 2014 planning policy guidance on viability (DCLG, 2014) was an attempt to 
resolve this. By stating how site value should be determined, it sought to fix it and therefore allow calculation of a viable amount of affordable housing. However, it is perhaps unsurprising that each party advocated an approach to the determination of site value that favoured their perspective. Developers focus on the land transaction evidence and claim that market prices set the benchmark whereas planning authorities focus on policy compliance and contend that a policy compliant level of affordable housing should be used to determine the site value. In this way, the appellant justified the $£ 13 \mathrm{~m}$ market site value input and the planning authority justified the $\mathrm{f} 6 \mathrm{~m}$ residual site value output.

PRL argued that $£ 6 \mathrm{~m}$ was so far below their $£ 13 \mathrm{~m}$ estimate of market value that the landowner would not be incentivised to sell, supporting this argument with an analysis of comparable evidence that showed land values comparable to the $f 13 \mathrm{~m}$ purchase price and levels of affordable housing comparable to the $14 \%$ in the planning application. The Council, however, sought to discredit this analysis. It showed that, when developments with no affordable housing requirement (such as schemes of less than ten dwellings and developments subject to permitted development rights) are removed, and when non-policy compliant evidence is adjusted to be compliant, then land prices fall. The proportion of affordable housing rises to levels commensurate with the Council's figures. This justified the use of a residual valuation that modelled $40 \%$ affordable housing. In other words, a modelled approach but using comparable evidence as a sense check on the proportion of affordable housing.

At appeal the Inspector placed greater weight on the appellant's market evidence than the Council's residual valuation and concluded that "...the appellant's land value figure can be regarded as adequately reflecting policy requirements on affordable housing" (Planning Appeal ref APP/V5570/A/14/2227656). Nevertheless, the appeal was dismissed on design grounds. On seeing its argument rejected by the Inspector, the Council proposed to seek judicial review of the decision claiming the Inspector had failed to consider policy compliance aspects of the appellant's land valuation. However, following legal advice, the Council decided against this course of action.

PRL submitted a revised planning application in January 2016. This time it was for 96 dwellings, none of which were to be affordable homes. The reduction in the number of units was presumably to address the design concerns that led to the original refusal. The Council again refused planning permission, solely on viability grounds, arguing that the appellant's approach to BLV was contrary to the 2014 viability guidance. They claimed that:

- The reduced size of the scheme was not reflected in the input site value. Instead the appellant sought to reduce the proportion of affordable housing in the same way that they did in the first application when the number of units was reduced from 150 to 112.

- The input site value does not reflect planning policy, which now includes the London Mayor's Supplementary Planning Guidance (Mayor of London, 2016) (the viability element of which was further revised in August 2017 (Mayor of London, 2017)), and Islington London Borough Council's Development Viability Supplementary Planning Document (London Borough of Islington, 2016). The former states that a market value approach to determining benchmark land value is only acceptable if it reflects all planning policy requirements and the latter states a preference for EUV+ as a basis for establishing BLV. In other words, the policy context for this second appeal was materially different to the first appeal. 
- Comparable evidence has not been adjusted to reflect differences in planning policy compliance, any growth assumptions that purchasers may have factored into their bids or any bidders' personal circumstances.

PRL appealed this second refusal of planning permission but it was dismissed once again. This time, however, the decision included a major turnaround in the Planning Inspectorate's approach to BLV compared to the first appeal. The Inspector stated that, even though the policy target for affordable housing does not apply to all individual sites, it should be the starting point for financial viability appraisals ${ }^{9}$. For this site, policy compliance means $50 \%$ affordable housing as there were no abnormal costs, a negligible EUV and no alternative use value. Also, rather than just using comparable sales transactions as direct evidence of BLV, adjustments should be made to make them comparable to the subject. In Paragraph 39 of the decision the Planning Inspector states that pure adherence to land transaction evidence without adjustment did not do justice to the first bullet point in Paragraph 23 (DCLG, 2014). The evidence needed to be adjusted to policy compliant levels of affordable housing; in this case $50 \%$.

The Inspector noted the difficulty in finding and adjusting comparable evidence, including the $f 13 \mathrm{~m}$ purchase price for the Parkhurst Road site itself, which lacked any supporting evidence of policy compliance. The Inspector regarded the appellant's analysis of comparable evidence as distorted because differences in affordable housing proportions were not adjusted for. Only one site had a proportion of affordable housing comparable to the $50 \%$ target and the Inspector gave weight to this evidence, which corroborated the Council's $f 7 \mathrm{~m}$ residual site value. The Inspector regarded the developer's approach as failing to give adequate effect to policy requirements for affordable housing and decided that it was acceptable for the Council to use EUV+ rather than the purely market-based approach advocated by the appellant.

PRL challenged the second appeal decision in the High Court ([2018] EWHC 991 (Admin)). Once again, the focus of disagreement between the two parties was BLV. The claimant, PRL, based its BLV on an analysis of comparable transactions and the purchase price, although the claimant never showed its appraisal in support of the $£ 13 \mathrm{~m}$ purchase price. The Council, using its analysis of comparable evidence adjusted for policy compliance, showed BLV to be much lower.

The High Court noted the different approaches to assessment of BLV by the parties. The Council contended that reference to the negligible EUV meant there was plenty of uplift to help pay for affordable housing. PRL argued that reference to negligible EUV was inappropriate and BLV should be based on market value; circularity would be avoided by disregarding transactions significantly above the market norm.

However, the High Court disagreed with PRL and found that "... what is to be regarded as comparable market evidence ... should reflect policy requirements in order to avoid the "circularity" problem..."

\footnotetext{
${ }^{9}$ Planning appeal reference number: APP/V5570/W/16/3151698 Paragraphs 18 and 49
} 
(paragraph 39). To achieve this, adjustments to comparables are required, and if adjustments are large then comparables may be assigned little or no weight. The High Court also disagreed with PRL on the matter of EUV; rather than finding reference to negligible EUV as inappropriate, as PRL argued, the High Court found that comparables differing markedly in terms of EUV would need careful consideration and adjustment. This finding aligns with the Council's view that the low EUV was a relevant factor in determining BLV.

The High Court ruled that the Inspector had not erred in law regarding the method of determining BLV and that errors in the Council's analysis of comparable evidence did not vitiate the dismissal of the appeal. The Inspector's criticisms that variables between sites were unknown and/or adjustments had not been made by PRL, still stood.

As a footnote to the decision, Judge Holgate raised some questions that have resounded through the planning and appraisal professional communities. In the final paragraph of his judgment (para 147), he made it clear that he thought that the "High Court is not the appropriate forum for resolving issues of the kind which the Inspectors dealing with the Parkhurst Road site had to consider. It is very much to be hoped that the court is not asked in future to look at detailed valuation material as happened in these proceedings." He also suggested that it might be an opportune moment to revisit the guidance from the RICS (2012) in order to address the issues raised by the Parkhurst Road case, primarily misunderstandings about market valuation concepts and techniques and the "circularity" issue. Evidence from other planning appeals shows that these questions have arisen in many development viability appraisals (Crosby and Wyatt, 2015); the Parkhurst Road case provides a unique and selfcontained example of the financial viability arguments from both sides and their subsequent resolution within the High Court.

\section{Discussion}

This research examines whether it is the imbalance of power and knowledge or the planning guidance that is the primary cause of viability disputes. The literature suggests that planners are familiar with the economics of development and recognise developer motivations, but much of the detail of financial viability modelling remains opaque to those outside of the development industry. The Parkhurst Road case demonstrates that, when resources and expertise are built up within local Government, this perceived imbalance can be countered.

Islington Council did not believe itself to be typical. According to a private email from one of the planning team at Islington, they believed that "very few if any other councils would have had the resources to take on Parkhurst Road successfully. The reasons for this were a combination of - a very clear prioritisation for affordable housing at a political and director level, a dedicated team and a period when there were not too many other competing priorities which meant that the council could focus on the case (the local plan and CIL charging schedule had already been adopted)". Islington drove research into this subject across 13 London Boroughs (Sayce, et al 2017) and utilised private sector and academic expert witnesses to match the experts of developers, landowners and their advisors. This is despite the costs and risks involved. "Appeals, particularly of this kind are so resource intensive and expensive that councils will often try to avoid them, particularly because of the budgetary pressures they have been under. The cost to Islington was significant but outweighed by the principles at stake in view of their 
priorities. Many other authorities would not have stuck to their position or gone to the same lengths to demonstrate their case ..".

As a result of this resistance, in London, where high land values and high demand for affordable housing have raised the stakes, knowledge and expertise within the public sector has grown, and this expertise has been harnessed by the Greater London Authority, which now has a three-person viability team, led by the original protagonist within Islington BC.

Parkhurst Road is the first viability case to reach the High Court, with the Judge obviously feeling that it should not have got there. It is a landmark case as it acts as a depository for the major issues which have dogged viability assessments and the determination of BLV. It addresses the role and analysis of market evidence and the meaning of policy compliance, and also how BLV is used within the wider modelling process.

The question remains as to the approach to the assessment of BLV that would have been practiced had the original planning inspector's approach been allowed to stand and replicated in similar cases. Another question remains concerning other local authorities who have not allocated resources, nor gained the expertise, and therefore unable to effectively counter any calculative practices to reduce the level of planning obligations.

A key technical issue is the tension between the first and third bullets in paragraph 23 of the PPG concerning policy compliance and the use of market evidence. First, does policy compliance mean what is actually being delivered or does it mean the target amount set out in the plan? In Parkhurst Road, the final decision was that it was the latter. But this raises two further questions: first, what if the plan does not specify an actual amount and second, should market evidence that is not policy compliant be adjusted to be policy compliant? The answers to these questions have significant implications for financial viability modelling.

Assuming appropriate market evidence can be identified, should the market value of the site based on those comparable transactions be inserted into the financial appraisal as a land cost, leaving the planning obligations as the residual amount? Or should the policy compliant level of planning obligations be inserted in the financial appraisal, leaving the land value as the residual amount, to be compared against market evidence? The former approach has been characterised as the classic manipulation of the calculation to create a circularity as set out in the literature review. The latter approach is favoured by local planning authorities. Once again, Parkhurst Road is helpful here as it presents a legal opinion on these two approaches. In the first appeal decision, the planning inspector assumed that the level of planning obligations in any market transaction was policy compliant, even if it was below the level set in a local plan. This meant that transaction prices were direct evidence for the land value inserted into a residual appraisal. In effect, he confirmed that the price paid was in line with other prices and duly inserted the market value unadjusted into the appraisal, leaving a low residual level of planning obligations. The revised appraisal adjusted the transaction evidence so that it complied with the target level of planning obligations stated in the local plan. The resultant land value was then inserted into the appraisal to identify the residual planning obligations. 
The new National Planning Policy Framework (MHCLG, 2018a) and Viability Guidance (MHCLG, 2018b), coupled with the decision on Parkhurst Road, has addressed several issues concerning the assessment of BLV within financial viability appraisals that have been raised in the literature. First, it removes the tension between policy compliance and market evidence by removing the bullet points in the old PPG paragraph 23. It states categorically that the plan should include specific amounts for developer contributions and that policy compliance means the provision of the plan levels of contributions and so the BLV should be based on levels in the plan and not based on what is being delivered under the old regime. Second, it allows policy compliant land transactions to be considered but relegates them to cross-checking the BLV and not determining it. Third, it installs the Existing Use Value plus a premium as the primary basis of setting the BLV.

Under the old guidance, parties could in effect choose whether to adopt an approach based on market value or on existing use value; a decision that became aligned with incentive. Local planning authorities advocate existing use value, not market value as used in Parkhurst Road. The revised viability guidance now endorses existing use value. The approach is rational; existing use value is an important indicator, if BLV is less than existing use value (or alternative use ${ }^{10}$ value) then the land will remain in its existing use (or switch to alternative use). Moreover, there seems little dispute that, to bring a site forward for development, there needs to be an incentive or premium above existing use value to motivate the landowner to sell or, to use the language of the old guidance, to offer a competitive return to the landowner.

The Government's new viability guidance is not silent on ways to determine the premium, but it does lack clarity. It suggests that the premium should be a minimum return to persuade a reasonable landowner to bring the site forward and implies that it can be "iterated" by discussion between the relevant parties and informed by professional judgment. Such discussions are likely to descend into the entrenched positions that have hitherto dogged viability negotiations. Perhaps pre-empting such an outcome, the viability guidance suggests how the quantum of the premium might be evidenced. Unfortunately, this is only likely to make the negotiation even more intractable.

Essentially, the new guidance states that the premium can be quantified by referring to market evidence, either in the form of BLVs from other viability appraisals or from market transactions. As indicated above, it places evidence from other viability assessments above that from land transactions. As far as valuation is concerned, the difference between these two may be hypothetical. This is because, once a few appraisals have been undertaken, their BLVs can be used as evidence for the next appraisal and so on (notwithstanding significant issues regarding the sources and adaptability of this kind of evidence). But where does the first BLV come from? If the answer is market evidence, how does deriving the premium in this way differ from deriving it directly from market evidence? In the absence of directly comparable premiums above existing use value, it is quite possible that valuers will revert to

\footnotetext{
${ }^{10} \mathrm{~A}$ use that would not require a fresh planning consent.
} 
normal valuation practice; which, for development land, is direct land transaction evidence and residual valuations (RICS, 2019). Any valuation guidance on viability appraisals needs to address these points.

If developers are able to use land transactions to set BLV and then insert it into the residual calculation, the 2014 PPG is virtually unchanged. The new rules concerning adjusting to policy compliant were included in Parkhurst Road, determined under the old PPG. BLV may be reported under the new guidance as EUV+ but the premium may have been extracted from the market evidence-based BLV. Many valuers, including some of those who drafted the RICS guidance in 2012, are wedded to market value so there will be support for this interpretation of the new guidance. The key issue here is not whether to use EUV + or market value, rather, it is to define site value rationally for financial viability appraisal and then determine a method to establish that value in each case. The premium in EUV+ then becomes the difference between EUV and policy compliant market value.

To summarise, the first potential change between the pre- and post-2018 approach to BLV should come from the Parkhurst Road High Court judgment now supported by the revised PPG. That change involves a movement away from direct transaction analysis without adjustment as proof of policy compliance to the adjustment of transactions to the price that would have been paid had the policy compliant levels of planning obligations been expected. However, this requires adherence to the new PPG requirement that all BLVs are based on a policy compliant level of planning obligations, and that plans adhere to the new requirement to set specific levels of required developer contributions in the plan.

The emphasis in viability appraisals should now focus on adjusting land prices to what they would have been assuming they were policy compliant. In the Parkhurst Road case PRL submitted an independent valuation of $£ 15.6$ million as evidence to support their $£ 13$ million site acquisition price and $14 \%$ affordable housing. However, the independent valuation assumed $16 \%$ affordable housing, which was not policy compliant if policy complaint is defined as the maximum amount set out in the plan. When it was adjusted to be policy compliant to that basis, i.e. $50 \%$ affordable housing, the valuation reduced to f7.32 million. Without such adjustment the benchmark land value simply uses high land prices to reduce affordable housing contributions. The High Court therefore rejected the evidence (or, more accurately, used it to verify the defendant's position on BLV). This decision, coupled with changes to policy guidance, provides the framework for the adjustment of market evidence to the stated levels of planning obligations set out in local authority planning policies.

But this change alone may not solve the gaming problem as it still puts land transaction evidence at the heart of the BLV assessment. A major issue is the application of the model and to what extent the model can be fine-tuned. The appraisal literature is scathing on the simplistic application of residual valuation techniques, the use of current (as opposed to forecast) costs and values, inappropriate inclusion of finance costs in a project appraisal and simplistic representations of profit. Both old and new versions of the viability guidance tolerate these methodological shortcomings to impose some consistency of method within financial viability appraisals. The incorporation of market evidence into models that did not generate this market evidence is inconsistent - sites are not being valued by the market and the model in the same way. This may mean that what appears to be an overpayment by a developer is in fact a perfectly rational price to pay for a development site that can still generate a competitive return to the developer and a full policy compliant level of planning obligations. The fact that this cannot be recognised within financial viability appraisals under the guidance is purely a function of the application 
of the wrong model. This mismatch between market pricing and viability modelling will produce inconsistencies between market evidence and model inputs and will cause the subsequent differences between the land price assessed by reference to land transaction evidence and that generated by a residual valuation model (Crosby, 2019).

So how could the application of the valuation model proceed? For site-specific viability assessments, the basic residual can now be used to determine a residual site value based on policy compliant planning obligations and a target developer return (some returns are now specified in the PPG). This policy compliant site value may not be very close to market values, but these will be assumed to be overbids made in the hope of reduced planning obligations in a former policy regime. There appears to be no reason for a planning authority to relax the policy compliant levels of planning obligations unless the residual site value falls close to or below existing or alternative use value. In such cases they might include a small premium to motivate the landowner to sell the site even though this premium has no theoretical framework or evidential underpinning. Given the lack of evidential underpinning, it would have to be stated in plans or supplementary guidance or emerge as custom and practice. There are instances in real estate appraisal where such premiums evolve from custom and practice: payments for ransom strips when development land is expropriated, and the apportionment of synergistic value are two examples.

Area-wide appraisals are designed to test new policies in relation to planning obligations, so they present an additional difficulty. What is the appropriate benchmark land value against which new (perhaps more onerous) levels of planning obligations should be tested? If market transactions are used to establish the benchmark land value, as they would have been transacted under a different policy regime, they will need adjusting to be compliant with new proposed policy. A new circularity is created as we do not know what the new policy levels are. These will have to be assumed as emerging policies.

Another solution is to estimate area-wide residual land values that assume no planning obligations and then compare these to existing use values. Any land value uplift is the amount available for both the landowner's premium and the planning obligations, which can be apportioned. There may be difficulty with equal apportionment where the uplift is small, on marginal brownfield schemes for example, and area-wide viability studies based on different typologies within planning areas might have different proportions if the landowner's portion is deemed too small to induce a sale of the land. Contrastingly, on greenfield sites where the uplift from agricultural EUV to residential land value can be substantial, the landowner's share may amount to a very large sum. There appears to be no appetite for this kind of solution; no doubt it will be viewed as a tax on development gains and politically unacceptable.

\section{Conclusion}

Christophers (2014) postulated that the modelling process now shapes reality, determining rather than reflecting the behaviour of landowners and developers. Viability modelling has certainly shaped Government policy and changes to the policy are designed to change the outcome of the modelling process due to an acceptance within Government that the process was capable of being gamed by developers and landowners. But Government viability policy has also begun the reshape development appraisal modelling in the UK, with more interest and attention from outside the practicing industry and 
a burgeoning literature. Not all of it is very complementary about technical expertise and understanding of technical aspects of the model and the way in which experts are applying it to viability in planning.

The emergence of financial viability appraisal in planning is a result of the increased role of non-planning experts in various components of the development management process. It is also evidence of the growing market orientation of planning. Landowners, advised by real estate appraisers and valuers, have been able to employ calculative practices in order to contest policies in relation to planning obligations and, in particular, affordable housing. Parkhurst Road shows that local planning authorities could also allocate resources to counter any possible asymmetry and reclaim some of the development gains lost to unequal power and knowledge.

The introduction of viability testing within the planning system has created a difficult balancing act between Government policy requirements; the delivery of housing targets while maintaining a flow of affordable housing within those targets. Without a fair split of development gains between the price paid to landowners, the profits to developers and the contribution to the community in the form of planning obligations, the policy objectives may not be achieved through the operation of the planning system. Unwittingly, the Government appears to have given both landowners and developers a windfall gain within its 2012 policy framework at the expense of the community. The new framework attempts to return the market to some sort of fair distribution between the three parties.

This paper has identified the 2018 changes to the 2012 planning policy and guidance as they refer to viability modelling within the planning system. This follows a landmark High Court case heard in the context of the old policy regime. That case concluded with the judge making a plea to the professional real estate community that additional advice on benchmark land value assessment was required over and above the professional advice already available.

The literature reveals how the introduction of financial viability into planning decision-making has created new challenges for the actors involved. The case study reveals that local authorities can access the same level of high quality technical support, but that depends on adequate funding of local government. Developers and landowners have long understood the benefits to be made from good technical support and expertise and how that can maximise their benefits. Will marketization within Local Government also enable them identify the increased returns that may flow their way from any increase in resourcing and technical expert support? Islington BC did prioritise and risk resources but felt that their response is atypical.

There are two further aspects of the new PPG which may support a more balanced negotiation within viability assessments. First, the move away from site-specific viability within the new PPG towards areawide. The increased emphasis should be followed by an increased resource for the area wide assessments which will be more complex with both strategic sites and a range of typologies being assessed. Second, the increase in transparency will enable assessments to be more easily scrutinised and data verified. This should make it more difficult for the private sector to use calculative practices hidden under the shroud of confidentiality to increase their share of the development gain.

This paper has examined how the gaming worked and suggested ways in which the same problems could be avoided within the technical context of development appraisal modelling. It identified different 
approaches to assessing Benchmark Land Value, the core of the viability test. This assessment is necessary because the Government, while specifying parameters for developers' return, failed to specify a similar metric for the landowner, knowing that any specification of landowners' return would be interpreted as a tax rate.

The revised policy and practice guidance have resolved some issues but may have replaced them with similar ones elsewhere. By potentially removing the circularity in site-specific viability appraisals, the Government has replaced it with another one in area-wide viability appraisals. Again the result of Government failing to state how much of the land value uplift should be retained by landowners and how much should go to the community. Without an unequivocal statement of landowner's return, it will remain a contested appraisal input and could, in turn, frustrate the estimation of a viable quantum of planning obligations in area-wide viability appraisals.

The unclear policy and guidance leave those responsible for advising stakeholders a significant problem. In effect, stakeholders and their advisors must set the land value capture tax rate, first on an area-wide basis and then on a site-by-site basis as appropriate. Presumably this is what Government means by iterative discussions between stakeholders in para 14 of PPG (MHCLG, 2018b). At the time of writing, the professional community is attempting to draft guidance in the light of the new policy and guidance and following the Parkhurst Road High Court decision. Given the lack of clarity in national policy and practice guidance, that will be no easy task.

Whatever solution is found, negotiations will still occur between the three stakeholders attempting to maximize their returns. Unless appraisal is taken out of the UK planning system altogether, of which there is no sign, variation in the outputs of the various valuations based on input uncertainty and more subtle variations in applications of those models, will ensure that viability negotiations will continue to play a major role in the ultimate balance of housing supply between delivery and affordability.

\section{References}

Adams D, Croudace R and Tiesdell S (2012) Exploring the 'notional property developer' as a policy construct, Urban Studies, 49(12): 2577-2596.

Adams D and Tiesdell S (2010) Planners and market actors: rethinking state-market relations in land and property, Planning Theory and Practice, 11(2): 187-207.

Christophers B (2014) Wild dragons in the city: Urban political economy, affordable housing development and the performative worldmaking of economic models. International Journal of Urban and Regional Research 38(1): 79-97.

Coiacetto E (2001) Diversity in real estate developer behaviour: a case for research, Urban Policy and Research, 19(1): 43-59.

Coleman C, Crosby N, McAllister P and Wyatt P (2013) Development appraisal in practice: Some evidence from the planning system, Journal of Property Research 30(2): 144-165.

Colenutt R, Cochrane A and Field M (2015) The rise and rise of viability assessment. Town and Country Planning, 84(10): 453-458. 
Crosby, N. (2019) Development viability assessment and the provision of affordable housing. A game of "pass the parcel"? Town Planning Review, 90 (4): 407-428.

Crosby, N. and Wyatt, P., (2015) Financial viability appraisal in planning decisions: theory and practice. London: RICS Research Trust.

Crosby N and Wyatt P (2016) Financial viability appraisals for site-specific planning decisions in England, Environment and Planning C: Government and Policy, 34(8): 1716-1733.

Crosby, N., Devaney, S. and Wyatt, P. (2019) Performance metrics, required returns and achieved returns for UK real estate development. London: RICS Research Trust.

DCLG (2012) National Planning Policy Framework. London: Department for Communities and Local Government.

DCLG (2014) Planning Practice Guidance: Viability. London: Department for Communities and Local Government.

DCLG (2017) Planning for the right homes in the right places: consultation proposals. London:

Department for Communities and Local Government.

Flynn J (2016) Complete control: Developers, financial viability and regeneration at the Elephant and Castle. City, 20(2): 278-286.

Healey P (1991) Models of the development process: a review, Journal of Property Research, 8(3), 219238.

Healey P (1992a) An institutional model of the development process, Journal of Property Research, 9(1): 33-44.

Healey P (1992b) The reorganisation of state and market in planning, Urban Studies, 29(3/4), 411-434.

Healey $P$ and Barratt S (1990) Structure and agency in land and property development processes: some ideas for research, Urban Studies, 27(1): 89-104.

Henneberry J and Parris S (2013) The embedded developer: using project ecologies to analyse local property development networks, Town Planning Review, 84(2): 227-249.

Local Housing Delivery Group (2012) Viability Testing Local Plans: Advice for Planning Practitioners. London: Local Housing Delivery Group.

London Borough of Islington (2016) Development Viability. Supplementary Planning Document. London: London Borough of Islington

McAllister P, Wyatt P and Coleman C (2013). Fit for policy? Some evidence on the application of development viability appraisals in the United Kingdom planning system, Town Planning Review, 84(4), 495-521.

McAllister P (2017) The calculative turn in land value capture: Lessons from the English planning system, Land Use Policy, 63: 122-129.

McAllister, P., Shepherd, E. and Wyatt, P. (2018) Policy shifts, developer contributions and land value capture in London 2005-2017. Land Use Policy, 78. pp. 316-326.

Mayor of London (2016). Housing: Supplementary Planning Guidance. London: Mayor of London.

Mayor of London (2017). Homes for Londoners: Affordable Housing and Viability Supplementary Planning Guidance. London: Greater London Authority.

MHCLG (2018a) National Planning Policy Framework. London: Ministry of Housing, Communities and Local Government.

MHCLG (2018b) Planning Practice Guidance: Viability. London: Ministry of Housing, Communities and Local Government. 
Monk S and Whitehead C (1999) Evaluating the economic impact of planning controls in the United Kindom: some implications for housing, Land Economics, 75(1), 74-93.

Parker G, Street E and Wargent M (2018) The rise of the private sector in fragmentary planning in England, Planning Theory and Practice, 19(5): 734-750.

Raco, M., Street, E., \& Freire-Trigo, S. (2016). The new localism, anti-political development machines, and the role of planning consultants: Lessons from London's south bank. Territory, Politics, Governance, 4(2), 216-240.

RICS (2012) Financial Viability in Planning. Guidance Note. London: Royal Institution of Chartered Surveyors.

RICS (2019) The Valuation of Development Property. Guidance Note. London: Royal Institution of Chartered Surveyors. (forthcoming).

Sayce S, Crosby N, Garside P, Harris R and Parsa A (2017) Viability and the Planning System: The Relationship Between Economic Viability Testing, Land Values and Affordable Housing in London, Royal Agricultural University, Kingston University, Ramidus Consulting and the University of Reading. https://s3-eu-west-

1.amazonaws.com/assets.henley.ac.uk/legacyUploads/pdf/schools/rep/Viability_and_the_Planning_ System_Research_January_2017.pdf

Table 1: Key inputs and outputs from the financial viability appraisals

\begin{tabular}{|l|c|c|}
\hline & $\begin{array}{c}\text { PRL's FVA } \\
\text { (14\% AH) }\end{array}$ & $\begin{array}{c}\text { Council's FVA } \\
\text { (40\% AH) }\end{array}$ \\
\hline Inputs: & & \\
\hline - Development value & $£ 57 \mathrm{~m}$ & $£ 43 \mathrm{~m}$ \\
\hline - Construction cost & $£ 36 \mathrm{~m}$ & $£ 30 \mathrm{~m}$ \\
\hline - Site value & $£ 13 \mathrm{~m}$ & - \\
\hline - Developer's profit & - & $£ 7 \mathrm{~m}$ \\
\hline Outputs: & & \\
\hline - Developer's profit & $£ 8 \mathrm{~m}$ & - \\
\hline - Site value & - & $£ 6 \mathrm{~m}$ \\
\hline
\end{tabular}




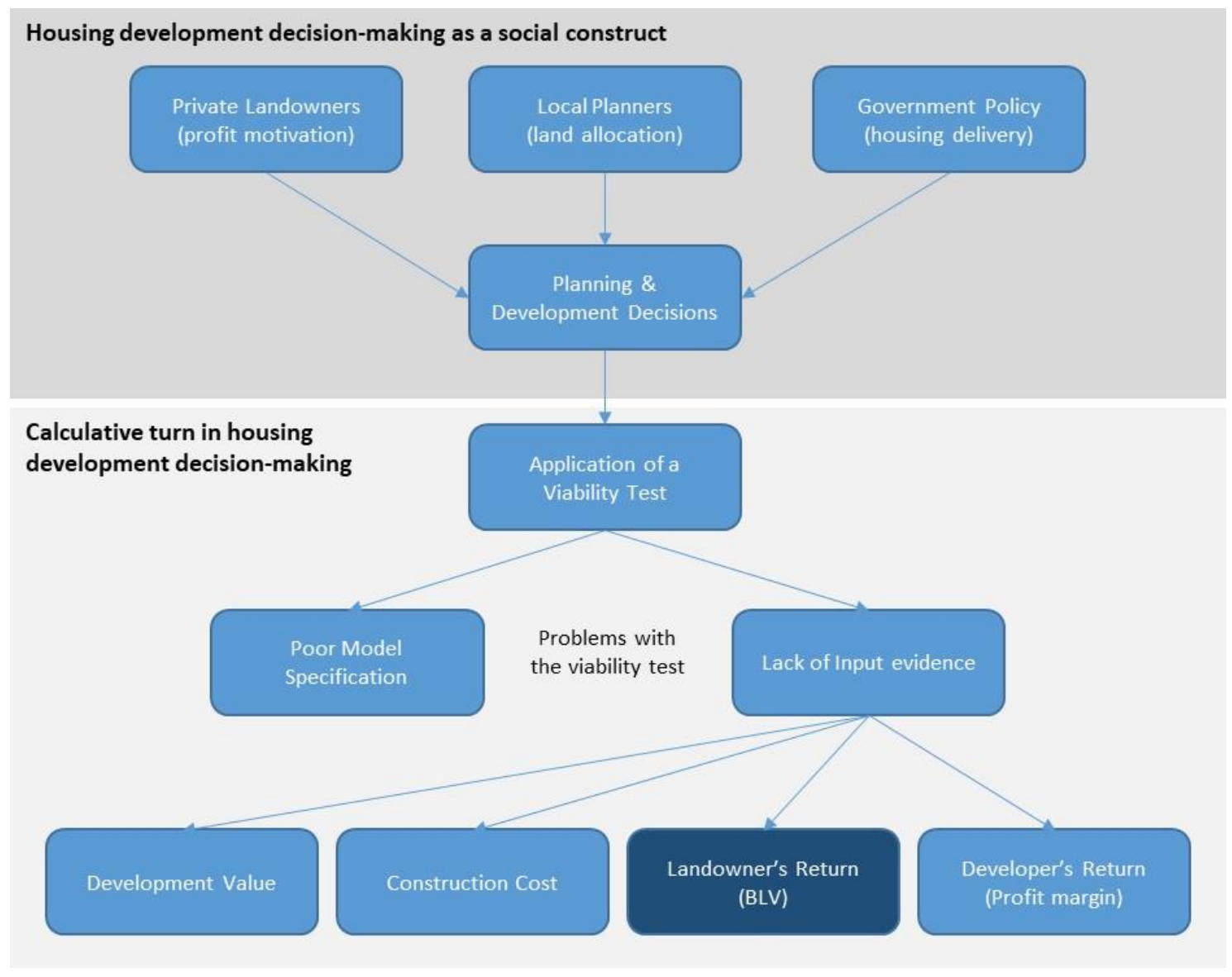

Figure 1: Housing development decision-making 